\title{
ESTRUTURA DO COMPONENTE ARBÓREO EM ÁREAS DE CERRADO NO MUNICÍPIO DE SÃO TOMÉ DAS LETRAS, MG ${ }^{1}$
}

Renata de Melo Ferreira Lopes², Valéria Lúcia de Oliveira Freitas ${ }^{3}$ e Paulina Maria Maia Barbosa ${ }^{4}$

\begin{abstract}
RESUMO - O município de São Tomé das Letras localiza-se ao sul de Minas Gerais, na bacia do rio Grande, em área de transição entre a Floresta Atlântica e o Cerrado, onde se distinguem também campos rupestres. Possui economia baseada em extrativismo mineral, agropecuária e turismo. Este trabalho teve como objetivo determinar a estrutura fitossociológica de três áreas de cerrado no município. Foram amostrados 60 pontosquadrantes por área, tomando-se medidas de altura das árvores e circunferência de tronco $(\geq 10 \mathrm{~cm})$ à altura do solo. Foram calculados para cada ambiente: densidade de indivíduos, dominância, frequência, área basal, Valor de Importância (VI) e diversidade florística (Índice de Shannon, H’). Ao todo, foram identificadas 27 famílias, 36 gêneros e 56 espécies. Eremanthus erythropappus (candeia, Asteraceae) foi a espécie de maior Valor de Importância (VI) encontrada nas áreas Candeias e Vale das Borboletas e Stryphnodendron adstringens (barbatimão, Fabaceae) e Piptocarpha rotundifolia (coração-de-negro, Asteraceae) as espécies que se destacaram em VI na área Carrapatos. A altura média variou de 2,0 $\pm 1,2$ a 2,3 $\pm 1,3 \mathrm{~m}$. O diâmetro médio variou de 6,5 $\pm 4,4$ a 7,3 $\pm 4,8 \mathrm{~cm}$. A densidade média foi de 2315 indiv.ha ${ }^{-1} \mathrm{e}$ área basal média de $13,4 \mathrm{~m}^{2}$.ha $\mathrm{ha}^{-1}$. O índice de diversidade de Shannon ( $H^{\prime}$ ) para espécies variou de 2,67 a 2,96 nats/ind. Foi observada baixa similaridade de espécies entre as três áreas. Considerando as pressões antrópicas que os ambientes naturais da região vêm sofrendo, os dados obtidos poderão subsidiar projetos locais de recomposição da vegetação, principalmente do componente arbóreo.
\end{abstract}

Palavras-chave: Fitossociologia; Serra da Mantiqueira; Mineração de quartzito.

\section{STRUCTURE OF THE TREE COMPONENT IN AREAS OF CERRADO IN SÃO TOMÉ DAS LETRAS, MG}

\begin{abstract}
The municipality of São Tomé das Letras is located in southern Minas Gerais state, in Serra da Mantiqueira, in the Rio Grande basin, in a transition zone between Cerrado and Atlantic Forest, where rupestrian fields are also found. The local economic activities are as follows: mineral extraction, agriculture and tourism. The objective of this study was to evaluate the phytosociological structure of three areas of cerrado in the municipality. Sixty quadrant-points were sampled per area by taking measures of height of the trees and trunk circumference at ground level $\geq 10 \mathrm{~cm}$. The following parameters were calculated for each environment: density of individuals, dominance, frequency, basal area, Importance Value, floristic diversity (Shannon index, $H^{\prime}$ '). Twenty-seven families, 36 genera and 56 species were identified. Eremanthus erythropappus (candeia, Asteraceae) was the species with the highest Importance Value (VI) in Candeias area and Vale das Borboletas area; Stryphnodendron adstringens (barbatimão, Fabaceae) and Piptocarpha rotundifolia (coraçãode-negro, Asteraceae) were the species with the highest VI in Carrapatos area. The most abundant species were Eremanthus erythropappus, Miconia albicans, Stryphnodendron adstringens and Myrsine guianensis. The average height ranged from $2.0 \pm 1.2$ to $2.3 \pm 1.3 \mathrm{~m}$. The average diameter ranged from $6.5 \pm 4.4$ to
\end{abstract}

\footnotetext{
${ }^{1}$ Recebido em 24.01.2012 aceito para publicação em 13.08.2013.

${ }^{2}$ Doutorado em Ecologia, Conservação e Manejo da Vida Silvestre na Universidade Federal de Minas Gerais, UFMG, Brasil. E-mail: <renatademeloferreira@yahoo.com.br>.

${ }^{3}$ Pesquisadora do Centro de Tecnologia Senai/Cetec, Gerência de Tecnologia Ambiental, Laboratório de Restauração Ecológica. Belo Horizonte, MG, Brasil. E-mail: <valeria.freitas@cetec.mg.gov.br>.

${ }^{4}$ Departamento de Biologia Geral da Universidade Federal de Minas Gerais, UFMG, Brasil. E-mail: <maia@icb.ufmg.br>.
}

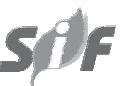

Revista Árvore, Viçosa-MG, v.37, n.5, p.801-813, 2013 
$7.3 \pm 4.8 \mathrm{~cm}$. For the three areas, the average density was 2,315 indiv. ha ${ }^{-1}$ and median basal area was 13.4 $\mathrm{m}^{2}$. ha $\mathrm{H}^{-1}$. The Shannon diversity index ( $H^{\prime}$ ) for species ranged from 2.67 to 2.96 nats/ind. Low similarity among areas was observed. Considering anthropic pressures that natural local environments are suffering, these results can subsidize local projects of the vegetation restoration, mainly of the arboreal component.

Keywords: Mantiqueira range; Phytosociology; Quartzite mining.

\section{INTRODUÇÃO}

O município de São Tomé das Letras está localizado na região sul do estado de Minas Gerais, na porção ocidental da serra da Mantiqueira, na bacia do rio Grande, sub-bacia do rio Verde, a 336 km de Belo Horizonte. Com população de 6.655 habitantes (IBGE, 2011), possui altitude média de 1290m, estendendo-se por uma área de $398 \mathrm{~km}^{2}$, limitando-se com os municípios de Três Corações, Luminárias, Conceição do Rio Verde, Baependi e São Bento do Abade. A economia do município está fundamentada em três atividades principais: o extrativismo mineral, que ocupa até 70\% da população ativa, a agropecuária e o turismo (DESCHAMPS et al., 2002), já que a cidade insere-se num complexo mineralógico de quartzito (pedra são tomé) e possui um patrimônio histórico datado do século XVIII (D’AURIA, 2000), além de formações naturais de grande beleza. A principal atividade econômica é, atualmente, a lavra do quartzito, geradora de degradação ambiental muito intensa e evidente, como alterações na topografia pelo acúmulo de rejeitos e empilhamento de estéreis (CHIODI, 2003).

A cobertura vegetal da região de São Tomé das Letras constitui-se de uma área de transição entre as florestas semidecíduas do sudeste e sul do país e o Cerrado do Brasil Central, com suas formações campestres como o campo sujo e o campo limpo, além de áreas significativas de campo rupestre (EITEN, 1972; RIBEIRO; WALTER, 2008; OLIVEIRA FILHO; FLUMINHANFILHO, 1999) e cerrado rupestre, uma formação vegetal que cresce sobre solo litólico, caracterizada por espécies arbustivo-arbóreas das demais formações savânicas (RIBEIRO; WALTER, 2008). Em geral, a cobertura vegetal da região do Alto Rio Grande encontra-se hoje reduzida a fragmentos de florestas, cerrado e campos, a maior parte dos quais mostra sinais de distúrbios por fogo, pecuária ou retirada seletiva de madeira para fins múltiplos (OLIVEIRA-FILHO et al., 1994a).

De acordo com Ferreira e Forzza (2009), os estudos sobre a vegetação da Serra da Mantiqueira estão restritos, em sua maioria, às formações florestais (BOTREL et al., 2002; CARVALHO et al., 1995; GAVILANES et al., 1992a, b; OLIVEIRA-FILHO et al., 1994a, b, c, d; RODRIGUES et al., 2003; SOUZA et al., 2003; VILELA et al., 1995, 2000; VAN DEN BERG; OLIVEIRA-FILHO, 2000), em detrimento de amostragens em áreas campestres. Segundo Drummond et al. (2005), a região de São Tomé das Letras é considerada de importância biológica muito alta devido à presença de campos rupestres que abrigam frágil vegetação, e de importância cultural devido à presença de pinturas rupestres, sendo a mineração e o turismo desordenado as pressões antrópicas mais importantes. De acordo com os autores, as recomendações específicas para essa região são a realização de inventários de flora e fauna e a criação de unidades de conservação.

O levantamento fitossociológico de remanescentes de vegetação que ocorrem próximos a áreas degradadas constitui ferramenta indispensável para a implementação de projetos de restauração ecológica. Esse tipo de recomposição vegetal utiliza espécies nativas e procura reconstituir a vegetação anterior considerando a diversidade de espécies da comunidade e a diversidade genética das populações originais (GONÇALVES et al., 1991). Dentro desse contexto, os objetivos deste trabalho foram descrever a estrutura da vegetação de três áreas de cerrado próximas à mineração de quartzito, em São Tomé das Letras (MG), verificar na literatura o que há publicado sobre as principais espécies, como forma de oferecer alternativa econômica sustentável à mineração, e indicar espécies para a restauração das áreas degradadas.

\section{MATERIAL E MÉTODOS}

O município de São Tomé das Letras, na bacia do rio Grande, Minas Gerais, apresenta pluviosidade média anual de 1.456 a 1.650 mm e clima tropical de altitude, com dias quentes e noites frias, temperatura anual média de $19^{\circ} \mathrm{C}$, mínima de $15^{\circ} \mathrm{C}$ e máxima de $26^{\circ} \mathrm{C}$ (INMET, 2011), época chuvosa entre os meses de outubro a março e época seca entre abril e agosto (NIMER, 1989). O trabalho foi desenvolvido no entorno de áreas degradadas pela mineração de quartzito. Foram realizadas 
cinco campanhas de campo durante os meses de junho a outubro de 2006. Para a análise fitossociológica, foram escolhidas três áreas de cerrado (Fig. 1), classificadas fitofisionomicamente segundo Ribeiro e Walter (2008), com diferentes perturbações antrópicas, assim

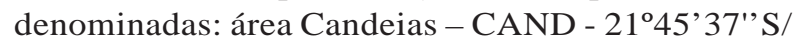
4459'37' 'W, cerrado sentido restrito a 974m de altitude, solo tipo Cambissolo Háplico Tb Distrófico (UNIVERSIDADE FEDERAL DE VIÇOSA et al., 2010), à beira de estrada de terra, contornada por pastagens;

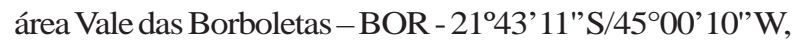
cerrado rupestre a $1013 \mathrm{~m}$ de altitude, solo do tipo Afloramento Rochoso(UNIVERSIDADE FEDERAL DE VIÇOSA et al., 2010), à beira da MG 868, a jusante de rejeitos de quartzito, e área Carrapatos, - CAR -

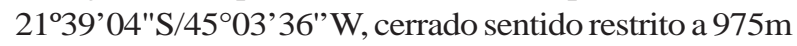
de altitude, solo Latossolo Vermelho-Amarelo Distrófico (UNIVERSIDADE FEDERAL DE VIÇOSA et al., 2010), à beira da MG 868, rodeada por pastagens. A amostragem foi realizada utilizando-se o método de ponto-quadrante (MARTINS, 1991). Em cada área foram demarcados 60 pontos-quadrantes distando $15 \mathrm{~m}$ entre si e $10 \mathrm{~m}$ da borda das trilhas. Em cada quadrante, foi amostrado o indivíduo vivo mais próximo ao ponto, com circunferência do tronco (CAS, ou circunferência à altura do solo), igual ou superior a $10 \mathrm{~cm}$. Cada indivíduo

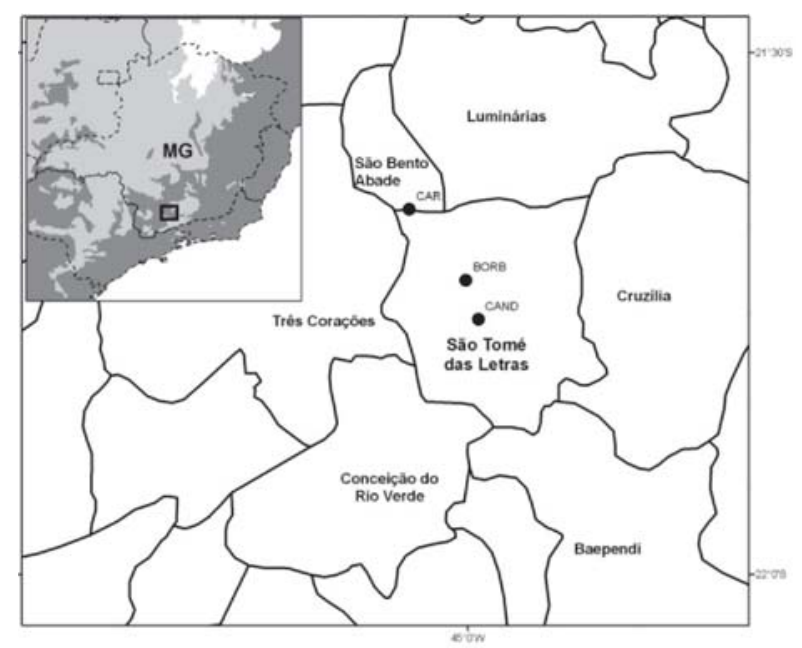

Figura 1 - Áreas amostradas no estudo fitossociológico em São Tomé das Letras, MG: CAND = área Candeias; BORB = área Vale das Borboletas; e CAR = área Carrapatos.

Figure 1 - Sampled areas in São Tomé das Letras, MG: CAND = Candeias area; BORB = Vale das Borboletas área; and CAR = Carrapatos area. recebeu um número de identificação por meio de etiquetas de plástico amarradas com fio de náilon. Para cada indivíduo foram registrados a CAS por meio de fita métrica, a altura total, com auxílio de podão, a distância do indivíduo ao ponto e a identificação prévia da espécie.

Foram feitas coletas de material vegetativo ou fértil, quando disponível, de todos os indivíduos amostrados no estudo fitossociológico, além das coletas de material fértil realizadas durante caminhadas pelo cerrado. A identificação taxonômica foi feita com base em literatura especializada, auxílio de especialistas e comparações com materiais dos herbários do Departamento de Botânica da Universidade Federal de Minas Gerais (BHCB) e Herbário da Fundação Centro Tecnológico de Minas Gerais (HXBX). A nomenclatura utilizada para as famílias seguiu a classificação utilizada pela APG III (2009). Os nomes populares foram definidos de acordo com a população local, Silva-Júnior (2005) e Silva-Júnior e Pereira (2009). Foram incluídas nas análises as morfo-espécies das plantas não identificadas, e as amostras férteis foram incorporadas ao herbário HXBX.

Para cada área foram analisados os seguintes parâmetros fitossociológicos: densidade absoluta e relativa, frequência absoluta e relativa, dominância absoluta e relativa, Valor de Importância (VI), como descritos em Müeller-Dombois e Ellenberg (1974). Para os cálculos utilizou-se o programa Fitopac 1 (SHEPHERD, 2001). As variáveis estruturais (diâmetro e altura médios) foram comparadas, entre as áreas, por análise de variância (ZAR, 1999). A diversidade entre as áreas foi comparada após cálculo do índice de diversidade de Shannon (ZAR, 1999), da equitabilidade correspondente (PIELOU, 1966) e a similaridade de espécies calculada pelo índice de Jaccard (MAGURRAN, 2004).

\section{RESULTADOS}

Considerando-se todas as áreas amostradas, foram encontradas 27 famílias, 36 gêneros e 56 espécies (Tabs. 1 e 2). As famílias com maior número de espécies foram: Fabaceae, Asteraceae, Malpighiaceae, Melastomataceae e Vochysiaceae. Os gêneros com maior número de espécies foram Byrsonima, Miconia, Eugenia e Myrcia e as populações com maior número de indivíduos foram de Eremanthus erythropappus (candeia, Asteraceae), Miconia albicans (pixirica-branca, Melastomataceae), Stryphnodendron adstringens (barbatimão, Fabaceae), Myrsine guianensis (capororoca, Primulaceae), Schefflera macrocarpa (mandiocão, Araliaceae), Piptocarpha 
Tabela 1 - Espécies arbóreas amostradas em três áreas de cerrado e número de indivíduos amostrados, em São Tomé das Letras, MG. (CAND = área Candeias; BOR = área Vale das Borboletas; CAR = área Carrapatos). HXBH = número de inserção no herbário CETEC.

Table 1 - Arboreal trees sampled in three areas of cerrado and number of individuals sampled in São Tomé das Letras, $M G$. $(C A N D=$ Candeias area $; B O R=$ Vale das Borboletas area CAR $=$ Carrapatos area $) . H X B H=$ accession number CETEC.

\begin{tabular}{|c|c|c|c|c|c|}
\hline \multirow{2}{*}{ FAMÍLIAS } & \multirow{2}{*}{ ESPÉCIES } & \multicolumn{3}{|c|}{ ÁREAS } & \multirow[b]{2}{*}{ HXBX } \\
\hline & & CAND & BOR & CAR & \\
\hline \multirow[t]{2}{*}{ Anacardiaceae } & Anacardium sp. & 0 & 6 & 0 & \\
\hline & Lithraea molleoides (Vell.) Engl. - aroeira & 0 & 0 & 1 & \\
\hline Annonaceae & Annona crassiflora Mart. - araticum & 0 & 1 & 0 & \\
\hline Araliaceae & Schefflera macrocarpa (Cham. \& Schltdl.) Frodin. - & 6 & 37 & 0 & 15.152 \\
\hline \multirow[t]{5}{*}{ Asteraceae } & Dasyphyllum sprengelianum (Gardner) & & & & \\
\hline & Cabrera - coroa-de-cristo & 1 & 0 & 0 & 15.153 \\
\hline & Eremanthus erythropappus (DC.) MacLeish - candeia & 49 & 19 & 0 & 15.154 \\
\hline & Eremanthus incanus (Less.) Less. - candeião & 7 & 7 & 0 & \\
\hline & Piptocarpha rotundifolia (Less.) Baker & 0 & 0 & 42 & 15.155 \\
\hline Bignoniaceae & Handroanthus sp. ipê & 1 & 0 & 0 & \\
\hline \multirow[t]{2}{*}{ Boraginaceae } & Cordia elliptica Sieber ex Griseb. & 1 & 0 & 0 & \\
\hline & Cordia trichotoma (Vell.) Arráb. ex Steud. & 1 & 1 & 0 & \\
\hline Burseraceae & Protium heptaphyllum (Aubl.) Marchand & 6 & 0 & 1 & \\
\hline Caryocaraceae & Caryocar brasiliense Cambess. - saco-de-cavalo & 9 & 2 & 0 & \\
\hline \multirow[t]{2}{*}{ Clusiaceae } & Clusia sp. & 1 & 18 & 0 & \\
\hline & Kielmeyera coriacea Mart. \& Zucc. & 11 & 6 & 24 & 15.156 \\
\hline \multirow[t]{2}{*}{ Erythroxylaceae } & Erythroxylum campestre A.St.-Hil. & 13 & 3 & 14 & 15.157 \\
\hline & Erythroxylum tortuosum Mart. & 7 & 3 & 16 & 15.158 \\
\hline Euphorbiaceae & Pera glabrata (Schott) Poepp. ex Baill. & 0 & 1 & 0 & 15.159 \\
\hline \multirow[t]{8}{*}{ Fabaceae } & Leptolobium dasycarpum (Vogel) & 2 & 0 & 28 & \\
\hline & Leptolobium subelegans (Mohlenbr.) Yakovlev & 2 & 0 & 0 & \\
\hline & Bauhinia rufa (Bong.) Steud. - pata-de-vaca & 1 & 0 & 2 & 15.160 \\
\hline & Copaifera langsdorffii Desf. - pau- d’óleo & 7 & 3 & 1 & \\
\hline & Dalbergia miscolobium Benth & 10 & 3 & 7 & \\
\hline & Fabaceae sp. & 1 & 0 & 0 & \\
\hline & Stryphnodendron adstringens & & & & \\
\hline & (Mart.) Coville - barbatimão & 2 & 9 & 42 & 15.161 \\
\hline Indeterminada & Indeterminada & 1 & 1 & 3 & \\
\hline Lythraceae & Lafoensia pacari A.St.Hil. & 1 & 0 & 0 & 15.162 \\
\hline \multirow[t]{4}{*}{ Malpighiaceae } & Byrsonima sp. & 3 & 0 & 0 & \\
\hline & Byrsonima intermedia A.Juss. & 1 & 0 & 0 & \\
\hline & Byrsonima verbascifolia (L.) DC. & 1 & 4 & 4 & 15.163 \\
\hline & Heteropterys byrsonimifolia A.Juss. & 2 & 0 & 0 & \\
\hline \multirow[t]{3}{*}{ Melastomataceae } & Miconia albicans (Sw.) Steud. & 27 & 35 & 3 & \\
\hline & Miconia sp.1 & 12 & 3 & 4 & 15.164 \\
\hline & Miconia sp.2 & 1 & 1 & 0 & 15.165 \\
\hline \multirow{8}{*}{ Myrtaceae } & Eugenia pluriflora Mart. & 0 & 0 & 1 & 15.167 \\
\hline & Eugenia punicifolia (Kunth) DC. & 1 & 1 & 1 & \\
\hline & Eugenia suberosa Cambess. & 0 & 0 & 7 & 15.168 \\
\hline & Myrcia obovata (O. Berg) Nied & 2 & 1 & 0 & \\
\hline & Myrcia rufipes Cambess. & 0 & 0 & 2 & \\
\hline & Myrcia splendens (Sw.) DC. & 0 & 0 & 1 & \\
\hline & Myrcia tomentosa (Aubl.) DC. & 0 & 0 & 9 & \\
\hline & Psidium cf. grandifolium (O. Berg) Burret & 0 & 0 & 1 & \\
\hline \multirow[t]{2}{*}{ Ochnaceae } & Ouratea hexasperma (A. St.-Hil.) Baill. & & & & \\
\hline & - vassoura-de-bruxa & 3 & 4 & 11 & 15.169 \\
\hline Primulaceae & Myrsine guianensis (Aubl.) Kuntze - capororoca & 20 & 28 & 3 & 15.166 \\
\hline Proteaceae & Roupala montana Aubl. - carne-de-vaca & 3 & 0 & 0 & 15.170 \\
\hline Rubiaceae & Palicourea rigida Kunth. - bate-caixa & 2 & 4 & 0 & 15.171 \\
\hline Rutaceae & Zanthoxylum rhoifolium Lam. - maminha-de-porca & 0 & 0 & 5 & \\
\hline Salicaceae & Casearia sylvestris Sw.- língua-de-tamanduá & 0 & 0 & 1 & \\
\hline Sapotaceae & Pouteria ramiflora (Mart.) Radlk. & 0 & 1 & 1 & \\
\hline Styracaceae & Styrax ferrugineus Nees e Mart. & 0 & 0 & 4 & 15.172 \\
\hline \multirow{2}{*}{ Vochysiaceae } & Qualea multiflora Mart. & 16 & 0 & 0 & \\
\hline & Vochysia thyrsoidea Pohl. - pau-vinho & 3 & 29 & 0 & \\
\hline \multirow{2}{*}{ Verbenaceae } & Vitex polygama Cham. & 3 & 7 & 0 & \\
\hline & Verbenaceae & 0 & 0 & 1 & \\
\hline TOTAL & & 240 & 240 & 240 & \\
\hline
\end{tabular}

Revista Árvore, Viçosa-MG, v.37, n.5, p.801-813, 2013 
rotundifolia (coração-de-negro, Asteraceae), Leptolobium dasycarpum (perobinha-do-campo, Fabaceae), Vochysia thyrsoidea (pau-vinho, Vochysiaceae) e Kielmeyera coriacea (pau-santo, Clusiaceae) (Tab.1).

A altura média variou de 2,0 \pm 1,2 (área Candeias) a 2,3 $\pm 1,3 m$ (área Carrapatos), diferenças estatisticamente significativas $\left(\mathrm{F}_{2,717}=3,63 ; \mathrm{p}=0,03\right)$ (Tab.2). O diâmetro médio variou de 6,5 \pm 4,4 (área Candeias) a 7,3 \pm 4,8 cm (área Vale das Borboletas) e não foi significativamente diferente para as três áreas $\left(\mathrm{F}_{2,717}=2,87 ; \mathrm{p}=0,06\right)$ (Tab.2). A densidade média foi de 2315 indiv.ha ${ }^{-1}$ e área basal média de 13,4 m².ha-1. A área Vale das Borboletas apresentou densidade de indivíduos inferior às demais áreas (Tab. 2). A diversidade de família e espécies e a equitabilidade foram semelhantes nas três áreas (Tab.3), a riqueza de gêneros e espécies não apresentou diferenças estatísticas (Tab.2). Mais de 60\% das famílias botânicas presentes nas áreas Vale das Borboletas e Carrapatos apresentaram apenas uma espécie (Tab.3). A similaridade de espécies entre as áreas foi baixa, sendo ligeiramente similares as áreas Vale das Borboletas, ou o cerrado rupestre e a área Candeias, cerrado sentido restrito (Tab.3).

Eremanthus erythropappus (candeia, Asteraceae) foi a espécie de maior Valor de Importância (VI) encontrada nas áreas Candeias e Vale das Borboletas e Stryphnodendron adstringens (barbatimão, Fabaceae) e Piptocarpha rotundifolia (coração-de-negro, Asteraceae) as espécies que se destacaram em VI na área Carrapatos (Fig. 2).

Tabela 2 - Número de famílias, gêneros e espécies e características estruturais do componente arbóreo, índice de diversidade de Shannon para espécies (H’, nats/indivíduo) e índice de equitabilidade de Pielou (J’) de três áreas de cerrado em São Tomé das Letras, MG (CAND = área Candeias; BOR = área Vale das Borboletas; e CAR = área Carrapatos). Letras diferentes indicam diferença estatística entre as médias das áreas, dada pela análise de variância.

Table 2 - Number of families, genera and species, and structural characteristics of the tree component, Shannon diversity index for species ( $\left.H^{\prime}\right)$ and Pielou equitability index ( $\left.J^{\prime}\right)$ in three cerrado areas in São Tomé das Letras, MG (CAND = Candeias area; $B O R=$ Vale das Borboletas area; $C A R=$ Carrapatos area). Different letters show statistical differences among areas by analysis of variance.

\begin{tabular}{|c|c|c|c|c|c|c|c|c|c|}
\hline ÁREA & $\mathrm{N}$ fam. & N gên. & $\mathrm{N}$ esp. & $\begin{array}{c}\text { Diâmetro } \\
\text { médio }(\mathrm{cm})\end{array}$ & $\begin{array}{l}\text { Altura média } \\
(\mathrm{m})\end{array}$ & $\begin{array}{c}\text { Densid. } \\
\text { (indiv.ha }^{-1} \text { ) }\end{array}$ & $\begin{array}{c}\text { Área basal } \\
\left(\mathrm{m}^{2} \cdot \mathrm{ha}^{-1}\right)\end{array}$ & $\begin{array}{c}\text { H’ } \\
\text { espécies }\end{array}$ & $\begin{array}{c}\text { J' } \\
\text { (equitabilidade) }\end{array}$ \\
\hline CAND & 19 & 29 & 38 & $6,5 \pm 4,4 a$ & $2,0 \pm 1,2 b$ & 2461,38 & 13,08 & 2,965 & 0,815 \\
\hline BOR & 19 & 23 & 28 & $7,3 \pm 4,8 a$ & $2,1 \pm 1,3 a b$ & 1961,78 & 14,65 & 2,712 & 0,814 \\
\hline CAR & 17 & 25 & 30 & $7,2 \pm 3,4 a$ & $2,3 \pm 1,3 a$ & 2522,65 & 12,38 & 2,674 & 0,786 \\
\hline
\end{tabular}

Tabela 3 - Porcentagem de indivíduos pertencentes às famílias com o maior número de indivíduos amostrados; porcentagem de famílias representadas por uma espécie e porcentagem de espécies ocorrentes somente na área em questão, nas três áreas de cerrado em São Tomé das Letras, MG (CAND = área Candeias; BOR = área Vale das Borboletas; e CAR = área Carrapatos).

Table 3 - Percentage of individuals belonging to families with most numbers of individuals sampled; percentage of families represented by only one species, and percentage of species occurring in only one area in the three cerrado areas in São Tomé das Letras, MG (CAND = Candeias area; BOR = Vale das Borboletas area; and CAR = Carrapatos area $)$.

\begin{tabular}{|c|c|c|c|}
\hline \multirow{2}{*}{ Famílias botânicas com a maior \% de indivíduos amostrados } & \multicolumn{3}{|c|}{$\%$} \\
\hline & CAND & BOR & CAR \\
\hline Fabaceae & 15,8 & 13,8 & 13,8 \\
\hline Asteraceae & 7,9 & 6,9 & 3,4 \\
\hline Malpighiaceae & 10,5 & 3,4 & 3,4 \\
\hline Melastomataceae & 7,9 & 10,3 & 6,9 \\
\hline Vochysiaceae & 7,9 & 3,4 & 0,0 \\
\hline Famílias representadas por uma espécie & 52,6 & 63,2 & 64,7 \\
\hline \multirow[t]{2}{*}{ Espécies ocorrentes somente nesta área } & 27,3 & 21,8 & 9,1 \\
\hline & CAND X BORB & CAND X CAR & BORB X CAR \\
\hline Similaridade (J’) entre as áreas & 0,56 & 0,31 & 0,32 \\
\hline Distância $(\mathrm{Km})$ entre as áreas & 4,8 & 13,8 & 9,8 \\
\hline
\end{tabular}


A

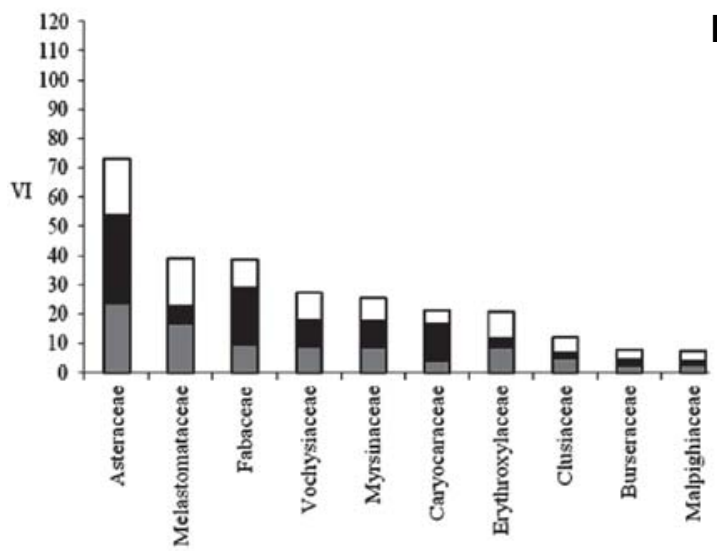

C

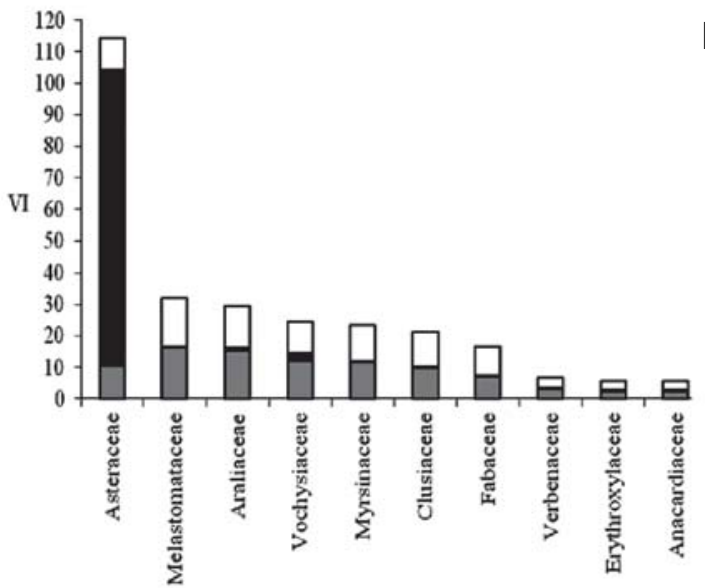

E

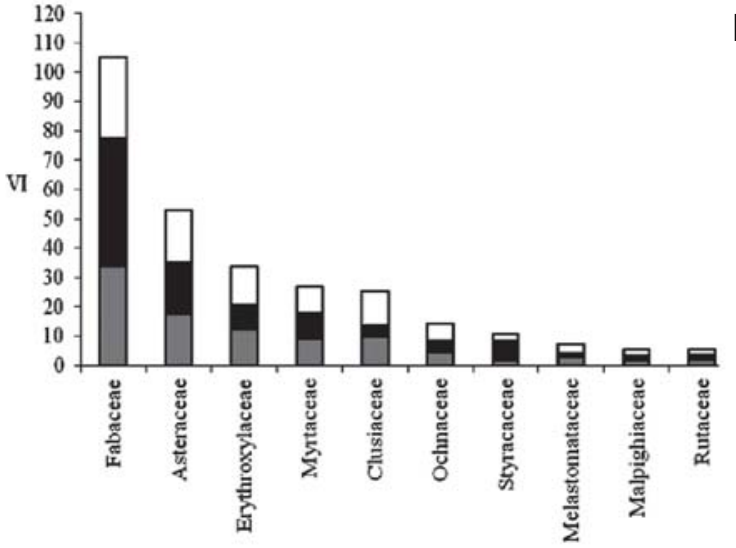

B

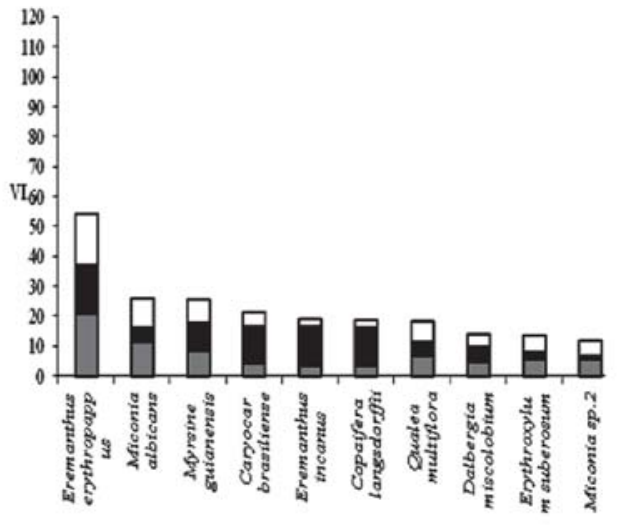

D

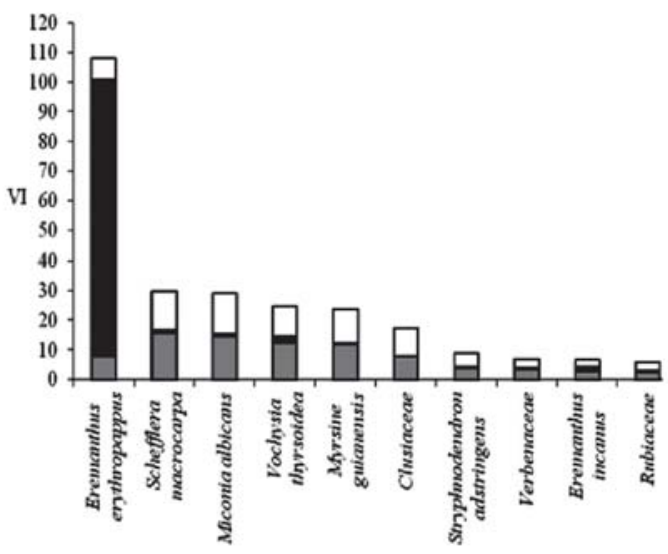

F

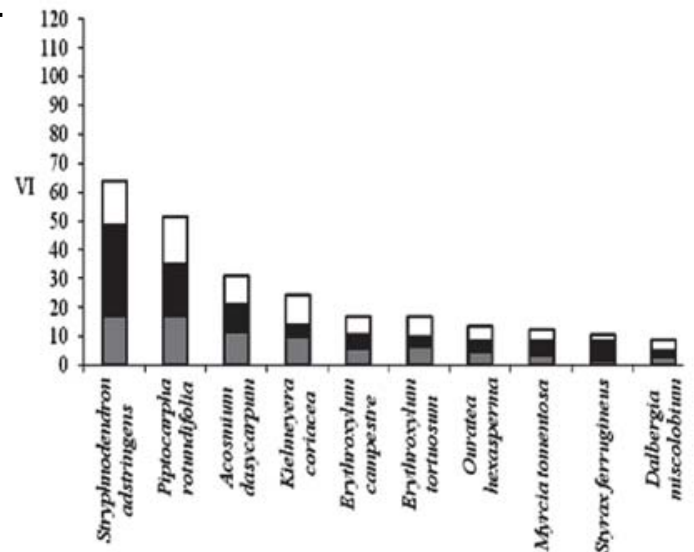

Figura 2 - Valor de Importância (VI) para famílias (A, C, E) e espécies (B, D, F) do componente arbóreo das três áreas de cerrado em São Tomé das Letras, MG. A,B = área Candeias; C,D = área Vale das Borboletas; E,F = área Carrapatos; Densidade relativa = barras cinzas; dominância relativa = barras negras; e frequência relativa = barras brancas.

Figure 2 - Importance Value (VI) for families ( $A, C$, E) and species $(B, D, F)$ of the tree component of three cerrado areas in São Tomé das Letras, MG. A,B = Candeias area; C,D = Vale das Borboletas area; E,F = Carrapatos area. Relative density = grey bars; relative dominance = black bars; and relative frequency $=$ white bars.

Revista Árvore, Viçosa-MG, v.37, n.5, p.801-813, 2013 


\section{DISCUSSÃO}

Oliveira-Filho e Fluminhan-Filho (1999) também encontraram indivíduos de Eremanthus erythropappus, Miconia albicans, Stryphnodendron adstringens, Myrsine guianensis, Schefflera macrocarpa, Vochysia thyrsoidea e Kielmeyera coriacea em áreas de cerrado do Parque Florestal Quedas do Rio Bonito, no Alto Rio Grande, sul de Minas Gerais. Estas foram as espécies mais abundantes registradas no presente estudo, juntamente com Leptolobium dasycarpum, sendo que Kielmeyera coriacea e Leptolobium dasycarpum também ocorreram, respectivamente, em $70 \%$ e $62 \%$ de 376 sítios de cerrado e savana amazônica (RATTER et al., 2003).

A família Fabaceae apresentou o maior número de espécies nas três áreas amostradas (Tab. 1). Essa família apresenta-se bem distribuída na região tropical, colonizando especialmente solos pobres em matéria orgânica, em sucessão secundária, sendo que algumas espécies possuem em suas raízes bactérias capazes de fixar nitrogênio atmosférico (SALISBURY; ROSS, 1992). Fabaceae foi também a família botânica com o maior número de indivíduos representados, em todas as áreas (Tab. 3), sendo Leptolobium dasycarpum e Stryphnodendron adstringens as espécies de maior Valor de Importância na área Carrapatos (Tab.1). Leptolobium dasycarpum é uma planta exclusiva do cerrado sentido restrito e dos cerradões, restrita ao Brasil, frutifica de março a junho, sendo os frutos dispersos pelo vento. Suas sementes possuem taxas altas de germinação. Tem potencial ornamental devido à bela folhagem e floração (SILVA-JÚNIOR, 2005) e propriedades alcalóides (TREVISAN et al., 2008).

Stryphnodendron adstringens é uma espécie arbórea típica das formações savânicas, principalmente do cerrado sentido restrito (EITEN, 1972; RIBEIRO; WALTER, 2008), com ampla distribuição geográfica, desde o Pará, atravessando o Planalto Central, até o norte do Paraná (FELFILI et al., 1999). É descrita como perenifólia, com frutos em algum estádio de maturação durante o ano todo e a dispersão parece ser zoocórica (OLIVEIRA; GIBBS, 2000). A dormência das sementes de $S$. adstringens permite à espécie superar condições ambientais desfavoráveis, como o fogo e os períodos de seca, que são comuns nas áreas de cerrado na sua época de frutificação e dispersão (FELFILI et al., 1999). A espécie é comercializada em mercados locais e regionais bem consolidados (FELFILI et al., 2004b). Foram observados alguns indivíduos com a casca do caule removida em alguns pontos, o que, segundo a comunidade local, é resultado do extrativismo feito na região (LOPES, obs. pessoal), uma vez que esta espécie possui propriedades cicatrizantes, adstringentes e antiinflamatórias (RODRIGUES; CARVALHO, 2001; SILVAJÚNIOR, 2005).

Já Asteraceae vem em segundo lugar, em relação ao maior número de indivíduos amostrados nas áreas (Tab. 3), especialmente devido ao grande número de Eremanthus nas áreas Candeias e Vale das Borboletas e Piptocarpha rotundifolia na área Carrapatos. Piptocarpha rotundifolia possui ampla distribuição pelo Cerrado brasileiro, no cerrado sentido restrito, campo cerrado, campo sujo e cerradão, frutifica de junho a agosto e suas sementes são dispersas pelo vento. Apresenta propriedades melíferas, sendo sua casca usada popularmente como curtume e no tratamento de sífilis, e flores e folhas usadas para artesanato (SILVAJÚNIOR, 2005).

Eremanthus erythropappus, a espécie de maior Valor de Importância encontrada nas áreas Candeias e Vale das Borboletas (Fig. 2), é uma espécie arbórea pioneira típica de regiões de maior altitude da região sudeste (SOUZA et al., 2007; JACOBI et al., 2008; SOELTL, 2009; FERREIRA; FORZZA, 2009; WERNECK et al., 2000). Sua madeira é resistente e durável, utilizada para mourão de cerca, e contém o óleo $\alpha$-bisabolol, utilizado na indústria farmacêutica e cosmética (SCOLFORO, 2002). Forma densas populações em campos e pastagens abertas, conhecidos como candeais, que se estabelecem pós-distúrbios. Os indivíduos de $E$. erythropappus e E. incanus são muito comuns em áreas de cerrado rupestre e campo rupestre de São Tomé das Letras. Nas áreas de mineração, observa-se grande número de plântulas e indivíduos adultos que crescem naturalmente sobre os rejeitos de quartzito.

O grande número de indivíduos de Stryphnodendron adstringens na área Carrapatos, com média de altura acima das médias de cada área (3,7m), assim como os de Eremanthus erythropappus na área Candeias, com média de altura de $2,3 \mathrm{~m}$, contribuiu para as diferenças estatísticas de altura encontradas entre as áreas. A área Vale das Borboletas, caracterizada como cerrado rupestre (EITEN, 1972; OLIVEIRA-FILHO; FLUMINHAN-FILHO, 1999; RIBEIRO; WALTER, 2008), 
apresentou densidade de indivíduos inferior às demais (Tab. 2) provavelmente devido à estrutura litólica do ambiente e conseqüente redução da formação de solo, fatores limitantes do crescimento de espécies arbóreas (RIBEIRO; WALTER, 2008).

Das espécies com os maiores VI encontrados na área Candeias (Fig.2), Caryocar brasiliense, Erythroxylum suberosum e Qualea multiflora também ocorreram em mais de 50\% dos 376 sítios de cerrado e savana amazônica amostrados por Ratter et al. (2003). Segundo este mesmo estudo, as espécies Miconia albicans, Myrsine guianensis, Copaifera langsdorffii, Dalbergia miscolobium e Erythroxylum suberosum também são frequentes em áreas de cerrado sentido restrito. Apesar de não ser uma espécie amplamente distribuída pelo Cerrado, Eremanthus erythropappus foi a que se destacou com o maior VI nesta área.

A composição florística do cerrado rupestre segundo Ribeiro e Walter (2008), representado neste trabalho pela área Vale das Borboletas, é caracterizada por espécies arbustivo-arbóreas das demais formações savânicas, principalmente do cerrado sentido restrito sobre solos profundos. Nessa área (Fig.2), estão aqui representadas especialmente as espécies de maior VI: Schefflera macrocarpa, Vochysia thyrsoidea, Myrsine guianensis e Stryphnodendron adstringens. Assim como na área Candeias, Eremanthus erythropappus foi a espécie que apresentou o maior VI. No cerrado rupestre, os indivíduos arbóreos são limitados em crescimento e densidade pelo volume de solo contido entre as fendas das rochas (RIBEIRO; WALTER, 2008).

Em relação à área Carrapatos, praticamente todas as suas espécies de maior VI são muito características do cerrado sentido restrito (Fig.2) (RATTER et al., 2003). Diferentemente das demais áreas, na área Carrapatos não foi registrado nenhum indivíduo de Eremanthus (Tab.1). As espécies que se destacaram em VI foram Stryphnodendron adstringens e Piptocarpha rotundifolia.

Trabalhos realizados sobre a vegetação lenhosa em 15 áreas de cerrado sentido restrito no Brasil Central obtiveram valores de $\mathrm{H}^{\prime}$ para espécies de 3,44 a 3,73 nats.ind $^{-1}$ (FELFILI et al., 2004a), superiores aos valores encontrados neste trabalho, que, por sua vez, mostraram-se semelhantes para as três áreas amostradas (Tab.3). Entretanto, históricos de perturbações e as condições locais de cada área podem ter sido determinantes para a diferenciação na riqueza de gêneros e espécies, como já descrito por Parket e Picket (1999), maior na área Candeias (Tab. 2). Já a presença de espécies comuns às áreas estudadas deve-se, provavelmente, à proximidade geográfica entre elas, com semelhanças nas condições ambientais locais, o que pode ter contribuído para obtenção de um índice de similaridade acima de 0,5 para as áreas Candeias (cerrado sentido restrito) e Vale das Borboletas (cerrado rupestre), que são as áreas mais próximas (Tab.3, Fig.1). No entanto, mais de 60\% das famílias botânicas presentes nas áreas Vale das Borboletas e Carrapatos apresentaram apenas uma espécie (Tab. 3), o que sinaliza para uma grande diversidade específica de famílias.

A cobertura vegetal lenhosa da área Carrapatos foi completamente cortada em junho de 2008 para fins agrícolas, evidenciando outra atividade degradadora, além da exploração de quartzito, que compete com a biodiversidade local. A área Vale das Borboletas foi parcialmente destruída pela mineração de quartzito, em 2009.

As espécies Eremanthus erythropappus (candeia, Asteraceae), Stryphnodendron adstringens (barbatimão, Fabaceae), Miconia albicans (quaresma-branca, Melastomataceae), Myrsine guianensis (capororoca, Primulaceae), Schefflera macrocarpa (mandiocão-docerrado, Araliaceae), Piptocarpha rotundifolia (coraçãode-negro, Asteraceae), Leptolobium dasycarpum (perobinha-do-campo, Fabaceae), Vochysia thyrsoidea (pau-vinho, Vochysiaceae) e Kielmeyera coriacea (pausanto, Clusiaceae) dominam em frequência de indivíduos e Valor de Importância nas áreas amostradas e, portanto, são recomendadas para estudos sobre sua utilização em programas locais de revegetação. No entanto, deve-se atentar para a importância da inclusão das demais espécies ocorrentes nas áreas em projetos de recomposição vegetal, de maneira que a riqueza e diversidade específica natural da região tornem-se preservadas.

Em relação às características ecológicas das demais espécies indicadas para utilização em programas de revegetação de áreas degradadas na região, foram colhidas algumas informações de interesse. Miconia albicans é uma arvoreta que alcança até três metros de altura, que ocorre desde o sul do México e Antilhas até o Paraguai e Paraná (GOLDENBERG, 2004). Ocorre em alta densidade em áreas secundárias regeneradas do Cerrado, bordas de florestas (ESPÍRITO-SANTO et al., 2002; NERI et al., 2005), solos rochosos e formações 
costeiras (GOLDENBERG, 2004). Seus frutos são pequenos e numerosos, esverdeados quando maduros, com alto conteúdo de água e carboidratos (MARUYAMA et al., 2007) utilizados por diversas espécies de aves frugívoras, em particular por aquelas oportunistas (SNOW, 1981).

Já Myrsine L. possui distribuição pantropical, com ocorrência de 26 espécies no Brasil (FREITAS; CARRIJO, 2010), sendo que as espécies arbóreas destacam-se nos processos naturais de sucessão (DORNELES; NEGRELLE, 2000). É uma espécie perenifólia, cuja maturação dos frutos é desencadeada pela diminuição da radiação e da temperatura no inverno. Fornece alimento para a avifauna local durante praticamente todo o ano (BAUER et al. 2012), sendo seus frutos dispersos por ela (PINESCHI, 1990; SIQUEIRA, 1993).

Schefflera macrocarpa é a mais amplamente distribuída espécie ocorrente na região sudeste que habita cerrados de terrenos baixos, com ocorrência concentrada em porções orientais do domínio (FIASCHI; PIRANI, 2007). É uma das espécies sempre-verdes que aparentemente captam água das camadas superficiais dos solos (JACKSON et al., 1999). Produz frutos de fevereiro a novembro, dispersos por animais, de cor vinácea quando maduros (SILVA-JÚNIOR, 2005). Já Vochysia thyrsoidea ocorre no cerrado sentido restrito e cerradões, no DF, BA, GO, MG, MT, MS, forma populações aglomeradas em afloramentos de quartzito e populações superiores a 1000m. Também é uma árvore sempre-verde, que frutifica de novembro a outubro, suas sementes são dispersas pelo vento e apresentam taxa baixa de germinação logo após a colheita (SILVAJÚNIOR, 2005).

A baixa taxa de germinação das sementes de Kielmeyera coriacea, bem distribuída ao longo do ano, é parte de uma estratégia que contribui para o sucesso do seu recrutamento nas fisionomias de savana do Cerrado. É uma das poucas espécies lenhosas que dominam na maioria das fisionomias abertas deste bioma (AOKIE SANTOS, 1982; RIBEIRO etal., 1985; ALMEIDA et al., 1998; SILVA-JÚNIOR, 2005). Os indivíduos possuem distribuição espacial agregada (OLIVEIRA et al., 1989) e alta frequência em áreas de cerrado sentido restrito (BARREIRA et al., 2002; REZENDE et al., 2005). Aespécie também é ornamental (MACEDO, 1991). Alguns indivíduos podem alcançar até oito metros de altura (ALMEIDA et al., 1998). Os frutos são deiscentes e grandes e após longo período de maturação, se abrem totalmente e as sementes podem ser facilmente destacadas e dispersas pelo vento, em sincronia com o início das chuvas (RIBEIRO et al., 1985; OLIVEIRA; SILVA, 1993; LANDIM; HAY, 1996).

\section{CONCLUSÃO}

Este trabalho pode ser útil para a região na medida em que caracteriza áreas com formações vegetais bastante ameaçadas, que se extinguem a cada dia ou se extinguiram parcialmente, como as áreas Carrapatos e Vale das Borboletas. Dessa forma, seus resultados podem auxiliar projetos locais de revegetação. Amanutenção da diversidade vegetal no município dependerá da conservação de remanescentes contínuos, da criação de unidades de conservação, do investimento em inventários de fauna e flora, da restauração das áreas degradadas pelas atividades econômicas da região e da sustentabilidade de atividades humanas, especialmente a extração de quartzito, a agropecuária e o turismo.

\section{AGRADECIMENTOS}

À FAPEMIG pelo apoio financeiro ao projeto, ao professor Dr. Marcos Sobral (UFSJ) pela identificação de Myrtaceae, à pesquisadora Dr. Sylvia Meyer (CETEC) pelo auxílio na identificação do material vegetativo, aos técnicos do laboratório de Restauração Ecológica do CETEC, José Carlos dos Santos e Giru Ferreira, pelo auxílio nos trabalhos de campo.

\section{REFERÊNCIAS}

ALMEIDA, P. D. et al. Cerrado: espécies vegetais úteis. Planaltina: Embrapa-CPAC, 1998.

AOKI, H.; SANTOS, I. R. Características dos estratos arbustivos e arbóreos do Distrito Federal. Silvicultura em São Paulo, v.16, p.626639, 1982.

THE ANGIOSPERM PHYLOGENY GROUP - APG III. An update of the Angiosperm Phylogeny Group classification for the orders and families of flowering plants: APG III. Botanical Journal of the Linnean Society, v.161, n.2, p.105-121, 2009.

BARREIRA, S. et al. Estudo da estrutura da regeneração natural e da vegetação adulta de um cerrado sensu stricto para fins de manejo florestal. Scientia Forestalis, v.61, n.1, p.64-78, 2002.

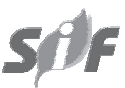

Revista Árvore, Viçosa-MG, v.37, n.5, p.801-813, 2013 
BAUER, D. et al. Fenologia de três espécies de Myrsine L. em floresta secundária semidecídua no Sul do Brasil. Revista Árvore, v.36, n.5, p.859-868, 2012.

BOTREL, R. T. et al. Influência do solo e topografia sobre as variações da composição florística e estrutura da comunidade arbóreoarbustiva de uma floresta estacional semidecidual em Ingaí, MG. Revista Brasileira de Botânica, v.25, n.2, p.95-213, 2002.

CARPANEZZI, A. A.; CARPANEZZI, O. T. B. Espécies nativas recomendadas para recuperação ambiental no Estado do Paraná, em solos não degradados. Colombo: Embrapa Florestas, 2006. 57p.

CARVALHO, D. A. et al. Flora arbustivo-arbórea de uma mata ciliar do Alto Rio Grande em Bom Sucesso - MG. Acta Botanica Brasilica, v.9, n.1, p.231-245, 1995.

CHIODI, D. K. Os quartzitos de São Tomé das Letras, Minas Gerais: principais demandas para o desenvolvimento sustentável da atividade produtiva. SEMINÁRIO SOBRE ARRANJOS PRODUTIVOS DE BASE MINERAL, 2003, Brasília. Anais... Brasília: Ministério de Minas e Energia, 2003. 9p.

D’ÁURIA, C. A. São Tomé das Letras na encruzilhada das fontes, dos tempos e dos saberes: um estudo sobre etnografia e historicidade com registros audiovisuais. Dissertação (Mestrado em Multimeios), Instituto de Artes, UNICAMP, Campinas, 2000.

DESCHAMPS, E. et al. Controle ambiental na mineração de Quartzito São Tomé. Belo Horizonte: Projeto Minas Ambiente, 2002. 201p.

DORNELES, L. P. P.; NEGRELLE, R. R. B. Aspectos da regeneração natural de espécies arbóreas da Floresta Atlântica. Iheringia, Série Botânica, v.53, n.1, p.85-100, 2000.

DRUMMOND, G. M. et al. Biodiversidade em Minas Gerais: um atlas para sua conservação. 2.ed. Belo Horizonte: Fundação Biodiversitas, 2005. 222p.
EITEN, G. The Cerrado vegetation of Brazil. Botanical Review, v.38, n.2, p.201-341, 1972.

ESPÍRITO-SANTO, F. D. B. et al. Variáveis ambientais e a distribuição de espécies arbóreas em um remanescente de floresta estacional semidecidual montana no campus da Universidade Federal de Lavras, MG. Acta Botanica Brasilica, v.16, n.3, p.331-356, 2002.

FELFILI, J. M. et al. Diversity, floristic and structural patterns of Cerrado vegetation in Central Brazil. Plant Ecology, v.175, n.1, p.37-46, 2004a.

FELFILI, J. M. et al. Potencial econômico da biodiversidade do Cerrado: estádio atual e possibilidades de manejo sustentável dos recursos da flora. In: AGUIAR, L. M. S.; CAMARGO, A. J. A. Cerrado: ecologia e caracterização. Planaltina: Embrapa Cerrados, p.177-220, 2004b.

FELFILI, J. M. et al. Estudo fenológico de Stryphnodendron adstringens (Mart.) Coville no cerrado sensu stricto da Fazenda Água Limpa no Distrito Federal, Brasil. Revista Brasileira de Botânica, v.22, n.1, p.83-90, 1999.

FERREIRA, F. M.; FORZZA, R. C. Florística e caracterização da vegetação da Toca dos Urubus, Baependi, Minas Gerais, Brasil. Biota Neotropica, v.9, n.4, p.131-148, 2009.

FIASCHI, P.; PIRANI, J. R. Estudo taxonômico do gênero Schefflera J.R. Forst. \& G. Forst (Araliaceae) na região sudeste do Brasil. Boletim de Botânica da Universidade de São Paulo, v. 25, p.95-142, 2007.

FREITAS, M. F.; CARRIJO, T. T. Myrsine In: Lista de Espécies da Flora do Brasil. Rio de Janeiro: Jardim Botânico do Rio de Janeiro, 2010.

GAVILANES, M. L. et al. Flórula da Reserva Biológica Municipal do Poço Bonito, Lavras, MG. III Formação florestal. Daphne, v.2, n.3, p.14-26, 1992a.

GAVILANES, M. L. et al. Flora arbustivo-arbórea de uma mata ciliar do Alto Rio Grande em Madre de Deus de Minas - MG. Daphne, v.2, n.4, p.15-24, 1992b. 
GOLDENBERG, R. O gênero Miconia

(Melastomataceae) no Estado do Paraná, Brasil. Acta Botanica Brasilica, v.18, n.4, p.927947, 2004.

GONÇALVES, J. C. et al. Recuperação de áreas degradadas. In: WORKSHOP SOBRE RECUPERAÇÃO DE ÁREAS DEGRADADAS, 1991, Itaguaí, RJ. Anais... Itaguaí: 1991. p.89-101, 1991.

\section{INSTITUTO BRASILEIRO DE GEOGRAFIA E} ESTATÍSTICA - IBGE. Disponível em:

<www.ibge.gov.br> Acesso em: 28 de out. de 2011.

INMET. Normais Climatológicas do Brasil 1961-1990. 2011. Disponível em: <www.inmet.gov.br> Acesso em: 23 de out. de 2011.

JACKSON, P. C. et al. Partitioning of soil water among tress in a Brazilian Cerrado ecosystem. Tree Physiology, v.19, p.714-724, 1999.

JACOBI, C. M. et al. Estudo fitossociológico de uma comunidade vegetal sobre canga como subsídio para a reabilitação de áreas mineradas no Quadrilátero Ferrífero, MG. Revista Árvore, v.32, n.2, p.345-353, 2008.

LANDIM, M. F.; HAY, J. D. Impacto do fogo sobre alguns aspectos da biologia reprodutiva de Kielmeyera coriacea Mart. Revista

Brasileira de Biologia, v.56, n.1, p.127-134, 1996.

MACEDO, J. F. Plantas corticosas do cerrado e sua utilização. Informe Agropecuário, v.15, n.168, p.33-37, 1991.

MAGURRAN, A. E. Measuring biological diversity. Oxford: Blackwell Publishing, 2004. 256p.

MARTINS, F. R. Estrutura de uma

floresta mesófila. Campinas: UNICAMP, 1991. 246p.

MARUYAMA, P. K. et al. Oferta qualitativa e quantitativa de frutos em espécies ornitocóricas do gênero Miconia (Melastomataceae). Revista Brasileira de Biociências, v.5, n.1, p.672-674, 2007.
MÜELLER-DOMBOIS, D.; ELLENBERG, H. Aims and methods of vegetation ecology. New York: Wiley \& Sons, 1974. 547p.

NERI, A. V. et al. Regeneração de espécies nativas lenhosas sob plantio de Eucalyptus em área de cerrado na Floresta Nacional de Paraopeba, MG, Brasil. Acta Botanica Brasilica, v.19, n.2, p.369-376, 2005.

NIMER, E. Climatologia do Brasil. 2.ed. Rio de Janeiro: IBGE: Departamento de Recursos Naturais e Estudos Ambientais, 1989.

OLIVEIRA, E. P.; SILVA, J. C. S. Reproductive biology of two species of Kielmeyera (Guttiferae) in the cerrados of Central Brazil. Journal of Tropical Ecology, v.1, n.1, p.67-79, 1993.

OLIVEIRA, P. E. A. M. et al. Estrutura e distribuição espacial de uma população de Kielmeyera coriacea Mart. de cerrados de Brasília. Revista Brasileira de Botânica, v.12, n.1, p.39-47, 1989.

OLIVEIRA, P. E.; GIBBS, P. E. Reproductive biology of woody plants in a cerrado community of Central Brazil. Flora 195: p.311-329, 2000.

OLIVEIRA-FILHO, A. T. et al. Comparison of the Woody flora and soils of six areas of montane semideciduous forest in southern Minas Gerais, Brazil. Edinburgh Journal of Botany, v.51, n.3, p.355-389, 1994a.

OLIVEIRA-FILHO, A. T. et al. Effect of flooding regime and understorey bamboos on the physiognomy and tree species composition of tropical semideciduous forest in Southeastern Brazil. Vegetatio, v.113, n.2, p.99-124, 1994 b.

OLIVEIRA-FILHO, A. T. et al. Estrutura fitossociológica e variáveis ambientais em um trecho da mata ciliar do córrego dos Vilas Boas, Reserva Biológica do Poço Bonito, Lavras (MG). Revista Brasileira de Botânica, v.17, n.1, p.67-85, 1994c.

OLIVEIRA-FILHO, A. T. et al. Composição florística e estrutura comunitária de um remanescente de floresta semidecídua montana em Lavras (MG). Revista Brasileira de Botânica, v.17, n.2, p.159-174, 1994d.

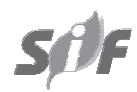

Revista Árvore, Viçosa-MG, v.37, n.5, p.801-813, 2013 
OLIVEIRA-FILHO, A. T.; FLUMINHAN-FILHO, M. Ecologia da vegetação do Parque Florestal Quedas do Rio Bonito. Cerne, v.5, n.2, p.51-64, 1999.

PARKER, V. T.; PICKET, S. T. A. Restoration as an ecosystem process: implications of the modern ecological paradigm. In: URBASKA, K. M.; WEBB, N. R.; EDWARDS, P. J. (Ed.).

Restoration and sustainable development. Cambridge: Cambridge University Press, p.17-32, 1999.

PIELOU, E. C. The measurement of diversity in different types of biological collections.

Journal of Theoretical Biology, v.13, p.131-144, 1966.

PINESCHI, R. B. Aves como dispersores de sete espécies de Rapanea (Myrsinaceae) no maciço do Itatiaia, estados do Rio de Janeiro e Minas Gerais. Ararajuba, v.1, n.1, p.73-78, 1990.

RATTER, J. A. et al. Analysis of floristic composition of the Brazilian Cerrado vegetation. III Comparison of the woody vegetation of 376 areas. Edinburgh Journal of Botany, v.60, n.1, p.57-109, 2003.

REZENDE, A. V. et al. Efeito do desmatamento no estabelecimento de espécies lenhosas em um cerrado sensu stricto. Floresta, v.35, n.1, p.6988, 2005.

RIBEIRO J. F. et al. Fitossociologia de tipos fisionômicos do Cerrado em Planaltina-DF. Revista Brasileira de Botânica, v.8, p.131-142, 1985.

RIBEIRO, J. F.; WALTER, B. M. T. As principais fitofisionomias do bioma Cerrado. In: SANO, S. M.; ALMEIDA, S. P.; RIBEIRO, J. F. (Ed.).

Cerrado: Ecologia e flora. Brasília, DF: Embrapa Informação Tecnológica, v.1. p.153-212, 2008.

RODRIGUES, L. A. et al. Florística e estrutura da comunidade arbórea de um fragmento florestal em Luminárias, MG. Acta Botanica Brasilica, v.17, n.1, p.71-87, 2003.

RODRIGUES, V. E. G.; CARVALHO, D. A. Plantas medicinais no domínio dos Cerrados. Lavras: Universidade Federal de Lavras, 2001. 180p.
SALISBURY, F. B.; ROSS, C. W. Plant physiology. 4.ed. Belmont: Wadsworth Publishing, 1992. 682p.

SCOLFORO, J. R. S. et al. Manejo sustentado das candeias Eremanthus erythropappus (DC.) e McLeisch Eremanthus incanus (Less.) Less. Lavras: Universidade Federal de Lavras, 2002. p.1-18, 2002.

SHEPHERD, G. J. Fitopac - Manual do usuário. Campinas: UNICAMP, 2001. 93p.

SILVA-JÚNIOR, M. C. S. 100 Árvores do Cerrado: guia de campo. Brasília: Rede de Sementes do Cerrado, 2005. 278p.

SILVA-JÚNIOR, M. C. S.; PEREIRA, B. A. S. + 100 Árvores do Cerrado - Matas de Galeria: guia de campo. Brasília: Rede de Sementes do Cerrado, 2009. 288p.

SIQUEIRA, J. C. O gênero Rapanea Aublet (Myrsinaceae) na região serrana do estado do Rio de Janeiro: aspectos taxonômicos e ecológicos das espécies. Pesquisas Série Botânica, v. 44, n.1, p.41-52, 1993.

SNOW, D. W. Tropical frugivorous birds and their food plants: A world survey. Biotropica, v.13, n.1, p.1-14, 1981.

SOELTL, T. M. Caracterização edáfica e vegetacional de espécies de Eremanthus sob litotipos distintos na Floresta Estadual de Uaimií, MG. 2009. 108f. Dissertação (Mestrado em Ciências Naturais) - Universidade Federal de Ouro Preto, Ouro Preto, 2009.

SOUZA, A. L. et al. Caracterização fitossociológica em áreas de ocorrência natural de candeia (Eremanthus erythropappus (D.C.) MacLeish. Revista Árvore, v.31, n.4, p.667-677, 2007.

SOUZA, J. S. et al. Análise das variações florísticas e estruturais da comunidade arbórea de um fragmento de floresta semidecídua às margens do rio Capivari, Lavras, MG. Revista Árvore, v.27, n.2, p.1-22, 2003. 
TREVISAN, T. C. et al. New quinolizidine and diaza-adamantane alkaloids from Leptolobium dasycarpum (Vog.) Yakovlev-Fabaceae.

Tetrahedron Letters, v.49, p.6289-6292, 2008.

UNIVERSIDADE FEDERAL DE VIÇOSA;

FUNDAÇÃO CENTRO TECNOLÓGICO DE MINAS GERAIS; UNIVERSIDADE FEDERAL DE LAVRAS; FUNDAÇÃO ESTADUAL DO MEIO AMBIENTE. Mapa de solos do Estado de Minas Gerais. Belo Horizonte: Fundação Estadual do Meio Ambiente, 2010.

van den BERG, E.; OLIVEIRA-FILHO, A. T.

Composição florística e estrutura fitossociológica de uma floresta ripária em Itutinga, MG, e comparação com outras áreas. Revista Brasileira de Botânica, v.23, n.3, p.231-253, 2000.
VILELA, E. A. et al. Flora arbustivo-arbórea de um fragmento de mata ciliar no Alto Rio Grande, Itutinga, Minas Gerais. Acta Botanica Brasilica, v.9, n.1, p.87-100. 1995.

VILELA, E. A. et al.. Caracterização estrutural de floresta ripária do Alto Rio Grande, em Madre de Deus de Minas, MG. Cerne, v.6, n.2, p.41-54, 2000.

WERNECK, M. S. et al. Florística e estrutura de três trechos de uma floresta semidecídua na Estação Ecológica do Tripuí, Ouro Preto, MG. Revista Brasileira de Botânica, v.23, n.1, p.97-106, 2000.

ZAR, J. H. Biostatistical analysis. 4.ed. New Jersey: Prentice-Hall, 1999. 663p. 
